\title{
A VOLUMINOUS LEFT ATRIAL MYXOMA IN A 62-YEAR OLD MAN WITH ATRIAL FIBRILLATION: A CASE REPORT AND REVIEW OF THE LITERATURE
}

\author{
Carma Karam Hôpital Ambroise Paré, AP-HP \\ Boulogne-Billancourt, Université \\ de Versailles-Saint Quentin en \\ Yvelines, France. \\ Lise Legrand Hôpital Ambroise Paré, AP-HP \\ Boulogne-Billancourt, Université \\ de Versailles-Saint Quentin en \\ Yvelines, France.
Nicolas Mansenca Hôpital Ambroise Paré, AP-HP Boulogne-Billancourt, Université de Versailles-Saint Quentin en Yvelines, France.
Olivier Dubourg Hôpital Ambroise Paré, AP-HP Boulogne-Billancourt, Université de Versailles-Saint Quentin en Yvelines, France.

\begin{abstract}
The incidence of primary tumors of the heart varies between 0.0017 and 0.19 percent in unselected patients at autopsy. Three of four tumors are benign and nearly half the benign heart tumors are myxomas. We present a case report of a 62-year-old caucasian man without known cardiovascular risk factors presented at the emergency room (ER) for palpitations. The initial EKG showed rapid atrial fibrillation around $100 \mathrm{bpm}$ and the patient complained of a recent dyspnea at exertion. Cardiac ultrasound was performed to rule out valvular or ischemic disease and measure the size of the left atrium. It showed a voluminous mass of $6 \mathrm{~cm} \times 5 \mathrm{~cm}$ in the left atrium. The surgical removal of the tumor was indicated and a CT scan of the coronary arteries was performed in this 62-year-old patient that showed mild stenosis on the LAD. The patient was sent to cardiac surgery. This case suggests that prompt surgical treatment was safe with a low operative mortality and good long term prognosis. Cardiac ultrasound was the method of choice for diagnosis and follow-up. Contrast echocardiography allowed differentiating between cardiac tumors, myxomas and thrombi in most cases due to the difference in vascularisation.
\end{abstract}

Keywords: Atrial mixoma; Echocardiography; Atrial fibrillation.

\section{INTRODUCTION}

The incidence of primary tumors of the heart varies between 0.0017 and 0.19 percent in unselected patients at autopsy. ${ }^{(1-4)}$ Three of four tumors are benign ${ }^{(1,5,6)}$ and nearly half the benign heart tumors are myxomas. They occur in all age groups but particularly between the 
third and sixth decades of life. ${ }^{(3,5,10,11)}$ Women predominate in most series..$^{(5,10,12-15)}$ They usually occur sporadically, but familial myxomas have been reported. ${ }^{(16-18)}$

Left atrial myxoma was first described in $1845 .^{(7)}$ and successful excision of a left atrial myxoma was reported in 1955. Cardiac myxomas usually develop in the atria, about three of four originate in the left atrium, and 15 to 20 percent in the right atrium. These tumors are of endocardial origin and project from the endocardium into the cardiac chamber. The rate of growth of these neoplasms is unknown, but they generally appear to grow rather quickly. ${ }^{(19-23)}$ The mobility of the tumor varies with the amount of collagen, the extent of attachment, and the length of the stalk. Polypoid myxomas are compact and show little tendency toward spontaneous fragmentation whereas papillary myxomas that are less common have multiple fine or very fine villous extensions at their surface that are gelatinous and fragile and tend to break off or into pieces. ${ }^{(3,11)}$ Embolism occurs in 30 to 40 percent of patients with myxomas..$^{(9,15,25,27-29)}$ In the majority of cases, the cerebral arteries, including the retinal arteries, are affected. Occlusions of peripheral arteries and embolization into visceral, renal, and coronary arteries can also occur. ${ }^{(4,11,12,19,24,29,30)}$

The treatment of choice is surgical removal that should be performed promptly, because of the possibility of embolic complications or sudden death. ${ }^{(10,14,38)}$ In most cases, cardiac myxomas can be removed easily and the root of the pedicle and the full thickness of the adjacent interatrial septum should be excised, with the resulting atrial septal defect closed by direct suturing or, if too large, with a pericardial or Dacron patch. ${ }^{(15,39,40)}$ The short- and long-term prognosis is excellent: in three series, the rate of operative mortality was 0 to 3 percent. ${ }^{(9,23,36)}$

\section{CASE REPORT}

A 62-year-old Caucasian man without known cardiovascular risk factors presented at the emergency room (ER) for palpitations. Few days before, he was seen by his family doctor for the same symptoms and had beta blockers (Atenolol $50 \mathrm{mg}$ ) prescribed once daily. At the $\mathrm{ER}$, the physical examination was unremarkable with a blood pressure of 112/87 $\mathrm{mm} \mathrm{Hg}$ and a height/weight of $180 \mathrm{~cm} / 90 \mathrm{~kg}$. The initial EKG showed rapid atrial fibrillation around 100 bpm and the patient complained of a recent dyspnea at exertion. Blood tests showed normal white and red blood cells and platelets counts and normal BUN.ABGs were also normal. 
Cardiac Troponin I level was 0.014 microg/L which is considered as normal and pro BNP was $7090 \mathrm{ng} / \mathrm{L}$. Ultrasensitive TSH value was 2.58 for a normal range of 0.27 to $4.20 \mathrm{mUI} / \mathrm{L}$.Creactive protein was normal $(4 \mathrm{mg} / \mathrm{L})$. The patient received anticoagulation and antiarrythmic therapy by intravenous digoxin.

Cardiac ultrasound was performed to rule out valvular or ischemic disease and measure the size of the left atrium. It showed a voluminous mass of $6 \mathrm{~cm} \times 5 \mathrm{~cm}$ in the left atrium with a pedicle arising from the interatrial septum, mobile, protruding into the left ventricle, hampering valve closure, leading to intermittent mitral insufficiency in addition to stenosis that is known as the "wrecking ball" effect (Figure 1). A contrast echocardiography using Sonovue contrast agent showed partial enhancement, suggesting myxoma (Figures 2 and 3).

The surgical removal of the tumor was indicated and a CT scan of the coronary arteries was performed in this 62-year-old patient that showed mild stenosis on the LAD. The patient was sent to cardiac surgery. The cardiac surgery consisted of an excision of the myxoma and the $1 \mathrm{~cm}$ square root of the pedicle. The resulting atrial septal defect was closed with a Dacron patch. In the absence of mechanical damage to the mitral valve leaflets, annuloplasty or replacement with a prosthetic valve was not needed.

Figure 1 - Cardiac ultrasound apical view showing a voluminous mass of $6 \mathrm{~cm} \times 5 \mathrm{~cm}$ in the left atrium with a pedicle arising from the interatrial septum, mobile, protruding into the left ventricle, hampering valve closure, leading to intermittent mitral insufficiency inaddition to stenosis that is known as the "wrecking ball" effect

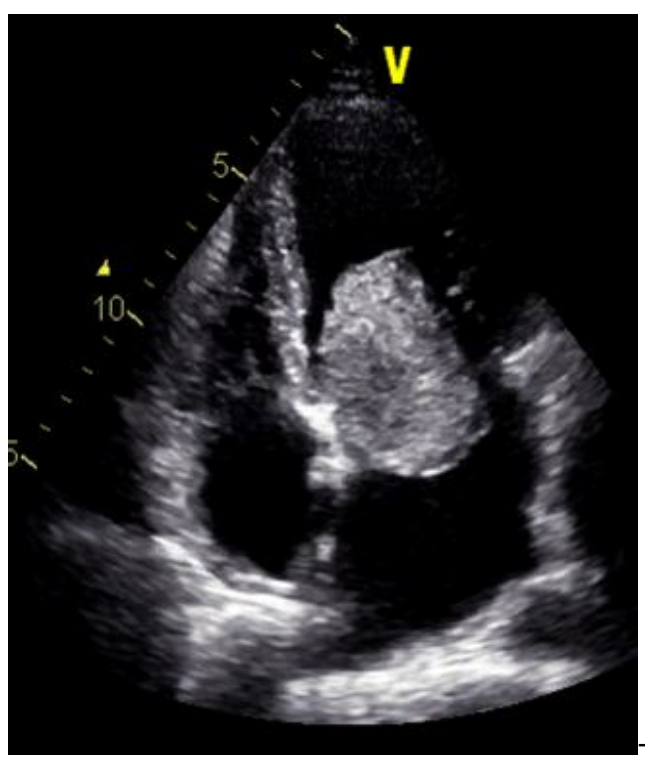


Figure 2 - Contrast echocardiography shows early images with the left ventricular cavity taking the contrast excluding the myxoma that is not taking the contrast yet

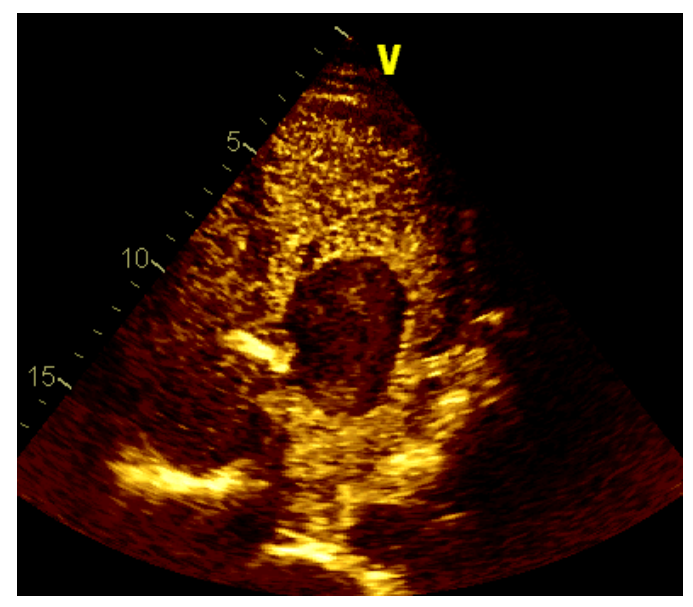

Figure 3 - Contrast echocardiography shows late images with partial and incomplete enhancement, suggesting myxoma. In contrast with a thrombus that is avascular, myxomas have blood supplies, with partial enhancement by contrast agent

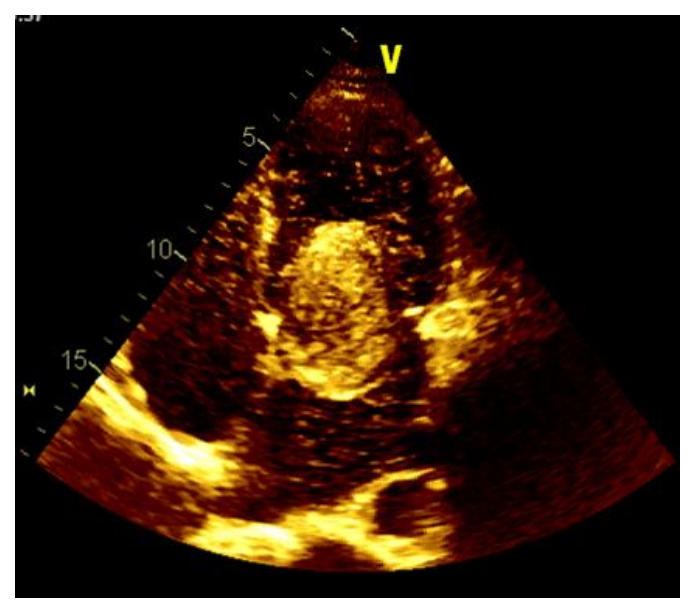

\section{DISCUSSION}

We report this case for several reasons. First, the patient's condition was unusual because of the male sex, since women predominate in most series. The clinical presentation was uncommon, since our patient presented no or mild symptoms. Myxomas of the left atrium commonly give signs as dyspnea or recurrent pulmonary edema, that mimic the clinical feature of mitral valve stenosis. In case of a large tumor, temporary complete obstruction of the orifice of the mitral valve may result in syncope or sudden death. $(9,12,13,25,27,28)$ 
Usually, the absence of symptoms is seen in the presence of small tumors. ${ }^{(3,25)}$ Other symptoms as fatigue, fever, and weight loss can be observed, as well as anemia generally normochromic or hypochromic, but also hemolytic and elevations in the the serum C-reactive protein level $^{(5,10,12,27,28,31-36)}$ The systemic signs disappear after the tumor has been removed. ${ }^{(12,37)}$ Another point of interest is the presence of an atrial fibrillation at the time of early diagnosis since the cardiac rhythm in myxomas is usually normal sinus, in contrast to the findings in mitral valve disease, and atrial fibrillation is uncommon. ${ }^{(25,36)}$

We performed contrast echocardiography since in our experience, ${ }^{(41)}$ in contrast with a thrombus that is avascular, myxomas have blood supplies, with partial enhancement by contrast agent. These characteristics allow differentiating between myxomas and thrombi as myxomas have partial or incomplete enhancement and thrombi have no enhancement at all. They also allow to differentiate between malignant tumors that have high blood supplies and abnormal neovascularization, with complete enhancement on contrast echocardiographic examination from myxomas who present partial enhancement as seen in our patient (Figure 2). Aditionnally, since priority should be given to prompt surgery we performed a CT scan instead of a coronary angiogram in a 63 -year-old patient, who had no risk factors for coronary artery disease and did not complain from chest pain or angina pectoris. CT scan was obtained in the same day as echocardiography and showed mild stenosis on the LAD without need for bypass surgery. We chose not to perform TEE before surgery since the TTE and contrast echocardiography gave confirmation of the diagnosis and because the extent of valvular obstruction varied with body position and we wanted to avoid complications as partial or total embolization in case of a bad tolerability of the TEE by the patient.

Finally, in some points, our patient's presentation is similar to that seen in atrial myxomas, since the tumor size was of $6 \mathrm{~cm}$ x $5 \mathrm{~cm}$. They usually range from 1 to $15 \mathrm{~cm}$ in diameter and most are 5 to $6 \mathrm{~cm} .^{(11,12)}$ The age of the patient is also common, myxomas are particularly encountered between the third and sixth decades of life. ${ }^{(3,5,10,11)}$

The location of the myxoma arising from the interatrial septum is the most frequently reported. ${ }^{(11,14)}$ The cardiac surgery consisted of an excision of the myxoma and the $1 \mathrm{~cm}$ square root of the pedicle. The resulting atrial septal defect was closed with a Dacron patch. 


\section{CONCLUSION}

Cardiac tumors are rare and benign are more common that malignant ones. Atrial myxoma is the most frequent benign cardiac tumor. Systematic echocardiography for isolated atrial fibrillation detected a voluminous left atrial myxoma in our 62-year-old patient, without obstructive or embolic complications. Prompt surgical treatment was safe with a low operative mortality and good long term prognosis. Cardiac ultrasound was the method of choice for diagnosis and follow-up. Contrast echocardiography allowed differentiating between cardiac tumors, myxomas and thrombi in most cases due to the difference in vascularisation.

\section{REFERENCES}

1. Benjamin HG. Primary fibromyxoma of the heart. Arch Pathol. 1939;27:950-950.

2. Straus R, Merliss, R. Primary tumor of the heart. Arch Pathol. 1945;39:74-78.

3. Heath D. Pathology of cardiac tumors. Am J Cardiol. 1968;21:315-327.

4. Wold LE, Lie JT. Cardiac myxomas: a clinicopathologic profile. Am J Pathol. 1980;101:219-240.

5. Griffiths GC. A review of primary tumors of the heart. Prog Cardiovasc Dis. 1965;7:465479 .

6. Silverman NA. Primary cardiac tumors. Ann Surg. 1980;191:127-138

7. King TW. On simple vascular growths in the left auricle of the heart. Lancet. 1845;2:428429.

8. Goldeberg HP, Glenn F, Dotter CT, Steinberg I. Myxoma of the left atrium: diagnosis made during life with operative and postmortem findings. Circulation. 1952;6:762-767.

9. John ST, Sutton MG, Mercier LA, Giuliani ER, Lie JT. Atrial myxomas: a review of clinical experience in 40 patients. Mayo Clin Proc. 1980;55:371-376.

10. Peters MN, Hall RJ, Cooley DA, Leachman RD, Garcia E. The clinical syndrome of atrial myxoma. JAMA. 1974;230:695-701.

11. Prichard RW. Tumors of the heart: review of the subject and report of one hundred and fifty cases. Arch Pathol. 1951;51:98-128. 
12. Goodwin JF. Diagnosis of left atrial myxoma. Lancet. 1963;1:464-468.

13. Bulkley BH, Hutchins GM. Atrial myxomas: a fifty year review. Am Heart J. 1979;97:639-643.

14. Livi U, Bortolotti U, Milano A, et al. Cardiac myxomas: results of 14 years' experience. Thorac Cardiovasc Surg. 1984;32:143-147.

15. Blondeau P. Primary cardiac tumors -- French studies of 533 cases. Thorac Cardiovasc Surg. 1990;38:Supp1 2:192-195

16. Liebler GA, Magovern GJ, Park SB, Cushing WJ, Begg FR, Joyner CR. Familial myxomas in four siblings. J Thorac Cardiovasc Surg. 1976;71:605-608.

17. Powers JC, Falkoff M, Heinle RA, et al. Familial cardiac myxoma: emphasis on unusual clinical manifestations. J Thorac Cardiovasc Surg. 1979;77:782-788.

18. Crawford FA JR, Selby JH JR, Watson D, Joransen J. Unusual aspects of atrial myxoma. Ann Surg. 1978;188:240-244.

19. Balk AHM, Wagenaar SS, Bruschke AVG. Bilateral cardiac myxomas and peripheral myxomas in a patient with recent myocardial infarction. Am J Cardiol. 1979;44:767-770.

20. Malekzadeh S, Roberts WC. Growth rate of left atrial myxoma. Am J Cardiol. 1989;64:1075-1076.

21. Roudaut R, Gosse P, Dallocchio M. Rapid growth of a left atrial myxoma shown by echocardiography. Br Heart J. 1987;58:413-416.

22. Pochis WT, Wingo MW, Cinquegrani MP, Sagar KB. Echocardiographic demonstration of rapid growth of a left atrial myxoma. Am Heart J. 1991;122:1781-1784.

23. Hanson EC, Gill CC, Razavi M, Loop FD. The surgical treatment of atrial myxomas: clinical experience and late results in 33 patients. J Thorac Cardiovasc Surg. 1985;89:298303.

24. De Morais CF, Falzoni R, Alves VAF. Myocardial infarct due to a unique atrial myxoma with epithelial-like cells and systemic metastases. Arch Pathol Lab Med. 1988;112:185-190.

25. Aldridge HE, Greenwood WF. Myxoma of the left atrium. Br Heart J. 1960;22:189-200.

26. Krikler DM, Rode J, Davies MJ, Woolf N, Moss E. Atrial myxoma: a tumour in search of its origins. Br Heart J. 1992;67:89-91.

27. Goodwin JF. The spectrum of cardiac tumors. Am J Cardiol. 1968;21:307-314.

28. Greenwood WF. Profile of atrial myxoma. Am J Cardiol. 1968;21:367-375. 
29. Silverman J, Olwin JS, Graettinger JS. Cardiac myxomas with systemic embolization: review of the literature and report of a case. Circulation. 1962;26:99-103.

30. Rath S, Har-Zahav Y, Battler A, Agranat O, Neufeld HN. Coronary arterial embolus from left atrial myxoma. Am J Cardiol. 1984;54:1392-1393.

31. Cohen AI, Mcintosh HD, Orgain ES. The mimetic nature of left atrial myxomas:report of a case presenting as a severe systemic illness and simulating massive mitral insufficiency at cardiac catheterization. Am J Cardiol. 1963;11:802-807.

32. Huston KA, Combs JJ JR, Lie JT, Giuliani ER. Left atrial myxoma simulating peripheral vasculitis. Mayo Clin Proc. 1978;53:752-756.

33. Kaminsky ME, Ehlers KH, Engle MA, Klein AA, Levin AR, Subramanian VA. Atrial myxoma mimicking a collagen disorder. Chest. 1979;75:93-95.

34. Thomas MH. Myxoma masquerading as polyarteritis nodosa. J Rheumatol. 1981;8:133137.

35. Fitzpatrick AP, Lanham JG, Doyle DV. Cardiac tumours simulating collagen vascular disease. Br Heart J. 1986;55:592-595.

36. Fang BR, Chiang CW, Hung JS, Lee YS, Chang CS. Cardiac myxoma:clinical experience in 24 patients. Int J Cardiol. 1990;29:335-341.

37. Seino Y, Ikeda U, Shimada K. Increased expression of interleukin 6 mRNA in cardiac myxomas. Br Heart J. 1993;69:565-567.

38. Thomas KE, Winchel CP, Varco RL. Diagnostic and surgical aspects of left atrial tumors. J Thorac Cardiovasc Surg. 1967;53:535-548.

39. Gerbode F, Kerth WJ, Hill JD. Surgical management of tumors of the heart. Surgery. 1967;61:94-101.

40. Dein JR, Frist WH, Stinson EB et al. Primary cardiac neoplasms: early and late resultsof surgical treatment in 42 patients. J Thorac Cardiovasc Surg. 1987;93:502-511.

41. Mansencal N, Revault-D'allonnes L, Pelage JP, Farcot JC, Lacombe P, Dubourg O. Usefulness of contrast echocardiography for assessment of intracardiac masses. Arch Cardiovasc Dis. 2009 Mar;102(3):177-83. 